\title{
PROCEDIMIENTO GUÍA PARA MANEJO SEGURO DE SUSTANCIAS QUÍMICAS EN UNA EMPRESA DE FABRICACIÓN DE SUELAS Y PLANTILLAS A BASE DE POLIURETANO DE LA CIUDAD DE CALI - COLOMBIA
}

\author{
PROCEDURE GUIDE FOR THE SAFE HANDLING OF CHEMICALS \\ IN A SOLE AND INSOLE MANUFACTURING COMPANY \\ A POLYURETHANE BASE FROM THE CITY OF CALI - COLOMBIA
}

\begin{abstract}
${ }^{1}$ Luis Alberto Vallejo Morán, ${ }^{2}$ Johanna Dominguez Orejuela, ${ }^{3}$ Iván Darío López Villalobos, ${ }^{4}$ Claudia Asceneth Castañeda Sanchez
\end{abstract}

1 Magister en Salud Ocupacional, Universidad Libre, Profesor Institución universitaria Antonio José Camacho, Santiago de Cali, Colombia

2 Profesional en Salud Ocupacional, Institución Universitaria Antonio José Camacho, Santiago Cali Colombia

3 Magister en Ingeniería Ambiental, Universidad Nacional de Colombia, Profesor Institución universitaria Antonio José Camacho, Santiago de Cali, Colombia

4Magister en Educación del Instituto Tecnológico y de Estudios Superiores de Monterrey, Profesor Institución universitaria Antonio José Camacho, Santiago de Cali, Colombia

\footnotetext{
${ }^{1}$ Ivallejo@admonuniajc.edu.co; ${ }^{3}$ idariolopez@admon.uniajc.edu.co;

${ }^{4}$ ccastaneda@admon.uniajc.edu.co
}

\section{RESUMEN}

Contextualización: para el manejo seguro de sustancias químicas, se identificaron las debilidades de la empresa objeto de estudio, en el manejo, uso, almacenamiento y transporte interno de sustancias químicas.

Vacío de conocimiento: este método contribuye como insumo para la gestión de sustancias que pueden dar lugar a posibles intoxicaciones por absorción e inhalación a trabajadores.
Propósito del estudio: el objetivo de este estudio es diseñar un procedimiento para manejo seguro de sustancias químicas en una empresa de fabricación de suelas y plantillas a base de poliuretano, lo que contribuirá a prevenir accidentes de trabajo y enfermedades laborales en los trabajadores de la empresa objeto de estudio; con un enfoque cuantitativo descriptivo observacional de corte transversal. 
Metodología: la investigación se realizó en una fábrica de suelas y plantillas a base de poliuretano de la ciudad de Cali (Colombia), y se incluyeron 33 trabajadores de los principales procesos productivos con exposición a sustancias químicas; se aplicó una encuesta para identificar el nivel de conocimiento de los empleados con respecto a las sustancias manejadas; se diseñó un cuestionario con base en normatividad colombiana, aplicándose el método simplificado para la evaluación del riesgo químico del instituto francés (INRS).

Resultados y conclusiones: según la tabla de determinación de riesgo, el análisis arrojó un resultado crítico para seis de las diez sustancias evaluadas. Se identificaron diez sustancias químicas consideradas peligrosas, cuatro de estas clasificadas como grupo A2, sospechosas de provocar cáncer, además de ser sustancias toxicas y nocivas para la salud y el medio ambiente. Se evidenció la ausencia de un procedimiento para el desarrollo de tareas críticas como lo es, el llenado de tanques, pintura e inyección, así como la falta de un programa de vigilancia epidemiológica para el monitoreo del personal con mayor exposición. Finalmente, se diseñó el procedimiento guía para manejo seguro de sustancias químicas y un plan de acción para implementación. La peligrosidad de algunas sustancias químicas a base de poliuretano utilizadas es alta, tanto que la agencia de Servicio de Salud Pública, la Agencia para Sustancias Tóxicas y el Registro de Enfermedades de EE.UU, cataloga a los isocianatos (TDI y MDI) como sustancias químicas muy reactivas.

Palabras clave: evaluación; peligro; riesgo químico; sustancia cancerígena; sustancias químicas.

\section{ABSTRACT}

Contextualization: For the safe handling of chemical substances, weaknesses of the company under study were identified, in terms of management, use, storage and internal transportation of chemical substances.

knowledge gap: This method contributes as an input to the substance management knowledge in relation to possible poisoning by absorption and inhalation by workers.

Purpose: The main aim of this study was to design a procedure for the safe handling of chemical substances in a company that manufactures polyurethane-based soles and insoles, helping to prevent workplace accidents and occupational diseases on workers at the company under study, with a cross-sectional descriptive, observational and quantitative approach.

Methodology: The study was carried out in a factory of soles and insoles based on polyurethane in Cali (Colombia) with 33 workers from the main production processes, who are exposed to chemical substances. A survey was applied to identify the knowledge level of employees regarding to the substance management. A questionnaire was designed, based on Colombian regulations, applying the simplified method for chemical risk assessment of the French Institute - INRS.

Results and conclusions: The analysis, according to the risk determination table, produced a critical result for six out of ten evaluated substances. Ten chemicals considered dangerous were identified and four of them were classified as group A2, suspected of causing cancer, being considered as toxic and harmful substances to health and environment. The absence of a procedure for the development of critical tasks such as filling tanks, painting and injection was evident, 
as well as the lack of an epidemiological surveillance program to monitor personnel with greater exposure. Finally, a procedure guide for the safe handling of chemical substances and an action plan for implementation were designed. The dangerousness of some chemical substances used based on polyurethane is high, so much so that the agency of Public Health Service, the Agency for Toxic Substances and the Registry of Diseases of the USA, lists isocyanates (TDI and MDI) as highly reactive chemicals.

Keywords: evaluation; danger; chemical risk; carcinogenic substance; chemical substances.

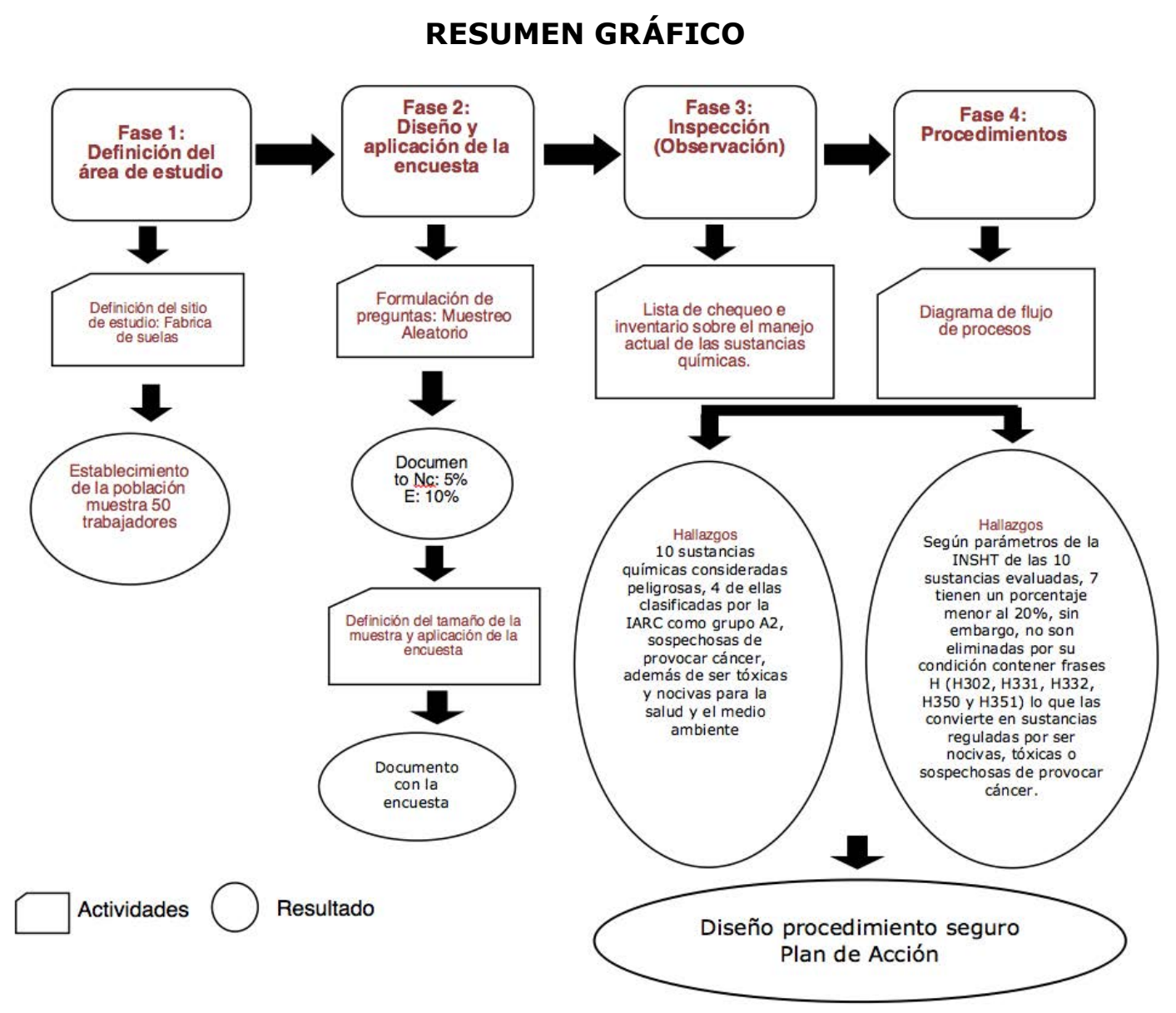

\section{INTRODUCCIÓN}

Los procesos realizados en la fabricación de suelas y plantillas para la industria del calzado involucran el uso de sustancias químicas peligrosas que pueden generar accidentes 0 enfermedades laborales. Según información del Consejo Colombiano de Seguridad CISPROQUIM, durante el primer semestre del 2011, se recibieron 4492 reportes de emergencia, con un aumento del $13 \%$, con respecto al mismo periodo del año 2010, en el que se reportaron 3974 casos. El Ministerio de la Protección Social de Colombia a través del Instituto Nacional de Cancerología, desarrolla desde el año 2013 el proyecto "Sistema de Vigilancia Epidemiológica del Cáncer Ocupacional" (SIVECAO) debido al problema de salud pública a nivel mundial del cual no es ajeno Colombia (Francelly Sánchez, 2014; Anaya Orbis, 2015; Calera A, 2005; OIT, 2014; Semarnat, 2010). 
En Colombia, el Decreto Único Reglamentario del sector trabajo 1072 de 2015, en su artículo 2.2.4.6.15, indica que, en la "Identificación de peligros, evaluación y valoración de los riesgos" Parágrafo 2, y según la naturaleza de los peligros, el empleador utilizará metodologías adicionales para complementar la evaluación de los riesgos en seguridad y salud en el trabajo ante peligros de origen químico (Ministerio de Trabajo, 2015; MAVDT, 2005). Más aun, cuando en el proceso productivo se involucran agentes potencialmente cancerígenos o de toxicidad aguda, se debe priorizar su intervención independientemente de sus dosis y el nivel de exposición (Anaya Orbis, 2015).

En la empresa objeto de este estudio, para el año 2017, se presentaron 13 accidentes de trabajo de los cuales 6 ocurrieron por causa del manejo inadecuado de sustancias químicas. Es por esta razón que esta investigación tiene como objetivo principal el diseño de un procedimiento guía para el manejo seguro de sustancias químicas en una empresa de fabricación de suelas y plantillas a base de poliuretano de la ciudad de Cali, Valle, en el 2018.

Inicialmente se realizó un diagnóstico y evaluación del riesgo químico por medio de la aplicación de una encuesta, lista de chequeo, inspecciones y la evaluación para la valoración del riesgo químico por inhalación o contacto con piel, metodología Simplificada propuesta por la INRS (Fasecolda, 2011).

Después se diseñó el Procedimiento para el manejo seguro de sustancias químicas dirigido, en principio, al conocimiento y valoración del riesgo, y luego a ofrecerle a la empresa una herramienta para intervenir el peligro químico, apoyo al cumplimiento de las normas y para el manejo seguro de sustancias químicas (Congreso de la República, 1993; Rodríguez S, 2008; Río, 2011). Finalmente se socializó el plan de acción del procedimiento guía para el manejo seguro de sustancias químicas en la empresa de fabricación de suelas y plantillas a base de poliuretano de la ciudad de Cali, Valle, 2018. Los objetivos planteados en este trabajo permitieron a la empresa reconocer la importancia de gestionar este peligro, además de controlar y prevenir los accidentes de trabajo derivados del manejo de sustancias químicas o futuras enfermedades laborales ocasionadas por la manipulación de estas (Granada Aguirre, et al., 2019).

\section{MATERIALES Y MÉTODOS}

Se realizó un estudio cuantitativo, descriptivo y observacional de corte transversal, en una fábrica de Suelas y Plantillas a base de Poliuretano en la ciudad Santiago de Cali. La población objeto de estudio fueron 50 trabajadores que intervienen en las labores de manejo, uso, almacenamiento, transporte interno y disposición final de las sustancias químicas o sus desechos, excluyéndose a los trabajadores del área administrativa, quienes no están en contacto con las sustancias químicas empleadas para el desarrollo de la labor.

\section{Análisis estadístico}

Se empleó un muestreo aleatorio simple de 33 trabajadores, con un margen de error del $10 \%$ y un nivel de confianza del $95 \%$. Se diseñó una encuesta basada en las características sociodemográficas y del grado de conocimiento del manejo de las sustancias químicas, que permitió identificar el cumplimiento de la normatividad colombiana en cuanto al riesgo químico (Alonso, 2014; Patiño Flores, 2017).

Adicionalmente, se realizó una inspección de observación en la que se tomaron registros fotográficos. Este diagnóstico aporta a la empresa un panorama sobre el manejo actual de las sustancias químicas y un procedimiento y plan de acción para la implementación según 
lo establece Naciones Unidas (2015) y como lo realizó Gisbert (2018).

Para determinar el grado de conocimiento del personal, se realizó una encuesta a 33 operarios de la empresa objeto de estudio con respecto a las sustancias químicas manejadas en la empresa, que se muestran en el Anexo 1. Se evaluaron las variables de la encuesta mediante estadística descriptiva, mostrando rangos, frecuencias, máximos y mínimos, en el caso de variables categóricas. Las relaciones entre variables se mostraron mediante graficas circulares, utilizando los programas estadísticos IBM SPSS versión 22 y $\mathrm{R}$ versión 3.6.1.

Se aplicó una lista de chequeo de 30 preguntas, que se muestra en el Anexo 2, en la que se evaluó el cumplimiento de aspectos generales, condiciones de manejo, uso, almacenamiento y disposición final de las sustancias químicas utilizadas en la empresa, con base en la normatividad colombiana vigente. La calificación se realizó con base en los parámetros que se muestran la Figura 1.

\begin{tabular}{|c|c|c|c|c|}
\hline \multirow{3}{*}{$\begin{array}{l}\text { CUMPLE } \\
\text { (1) }\end{array}$} & \multirow{3}{*}{$\begin{array}{l}\text { NO CUMPLE } \\
\text { (0) }\end{array}$} & \multirow{3}{*}{$\begin{array}{l}\text { RESULTADO } \\
\text { (Valoración de puntos } \\
\text { de cumplimiento) }\end{array}$} & 22 - 30 Puntos & Aceptable \\
\hline & & & $15-21$ Puntos & Aceptable con control específico \\
\hline & & & Menos de 14 Puntos & No aceptable \\
\hline
\end{tabular}

Figura 1. Parámetros de Calificación de la Encuesta.

Fuente: Autores

Se realizó un inventario de sustancias químicas acorde a Negrete (2014), que cuenta con información de la Composición, \# Cas, TLV, Frases $\mathrm{R}$ y $\mathrm{H}$, Efectos de la exposición, Toxicología, Efectos cancerígenos, mutagénicos y a la reproducción, Inflamabilidad y Reactividad de la sustancia, y pictogramas de peligro de acuerdo al SGA según Naciones unidas (2015). De igual manera, se aplicó el método para la evaluación por exposición a riesgo químico del (Institut National de Recherche et de Sécurité -INRS) Instituto Nacional de Investigación y Seguridad para la Prevención de Accidentes de Trabajo y Enfermedades Profesionales. La aplicación del método fue evaluada de acuerdo a los parámetros dados por este como se ve en la Tabla 1.

Tabla 1. Caracterización del riesgo por inhalación / contacto con la piel.

\begin{tabular}{c|c|l|}
\hline $\begin{array}{c}\text { Puntuación } \\
\text { de riesgo }\end{array}$ & $\begin{array}{c}\text { Prioridad } \\
\text { de acción }\end{array}$ & $\begin{array}{l}\text { Caracterización del riesgo Inhalación }=\text { Peligro x Volatilidad x } \\
\text { Procedimiento x Protección colectiva }\end{array}$ \\
\cline { 2 - 3 }$>1.000$ & 1 & Riesgo probable muy elevado (medidas correctivas inmediatas) \\
\hline $100-1.000$ & 2 & $\begin{array}{l}\text { Riesgo moderado. Es probable que necesite medidas } \\
\text { correctivas y una evaluación más detallada }\end{array}$ \\
\hline$<100$ & 3 & Riesgo a priori bajo (Sin necesidad de modificaciones) \\
\hline
\end{tabular}

Fuente: Instituto nacional de higiene y seguridad en el trabajo (2012) 


\section{Proceso de Fabricación de Suelas y Plantillas}

Como se muestra en la Figura 2, el proceso inicia con la inyección de las suelas. El líder de turno, junto con cinco operarios más, están encargados de sacar la producción de suela o plantillas según se requieran. Una de las seis personas deberá abastecer la máquina con las materias primas (isocianato, catalizador y poliol). Uno de los operarios es el encargado de realizar los cambios de moldes durante todo el turno, mientras los cuatro realizan las operaciones de inyección, aplicación de desmoldante y retirar las suelas. Ya estando la suela lista para pasar al refilado, hay una persona encargada de la calidad de las suelas, quien verifica la forma, el color y el acabado de las mismas. La suela que no cumpla con las especificaciones deberá ser nuevamente inyectada.

Posteriormente, se pasa al proceso de Refilado, en el que se quitan los sobrantes de material, se realiza una verificación de la cantidad que debe estar y se acomoda por bloques cada una de las órdenes que se deben pasar al siguiente proceso. Durante el lavado, se realiza la limpieza de la suela desmoldante, la cual fue usada en la inyección, además de otras impurezas que trae el producto. Esta actividad se hace con ayuda de una mezcla entre percloroetileno con agua en una lavadora industrial.

El siguiente proceso es el de pintura. Según sea necesario, las suelas pasan al área de pintura, donde 2 operarios abastecen las bandas transportadoras que llevan el producto terminado a las 3 cabinas de pinturas donde los operarios con pistolas rociadoras, las pintan y las vuelven a poner en la banda para ser transportadas el siguiente proceso. En el proceso de empaque, las suelas se organizan según orden de pedido y por último llegan al área de despachos, donde finaliza el proceso de producción de las suelas. Seguidamente, el proceso de aplicación de desmoldante se inicia al momento que el operario esparce la sustancia en el molde hasta el paso a la siguiente estación. A partir de allí, se inicia el Proceso de inyección, actividad que empieza con la primera acción del cabezal, y el derrame de sustancia sobre el molde, y termina al momento en que se detiene el derramado y se cierra la estación. Finalmente, el proceso de curado, realizado dentro del molde. se inicia al instante que el operario oprime el botón que da el cierre hermético y finaliza al momento que este molde realiza su apertura.

\section{DIAGRAMA DE FLUJO DE PROCES OS DE FABRICACIÓN}

\begin{tabular}{|l|l|}
\hline $\begin{array}{l}\text { NOMBRE DEL } \\
\text { PROCES O }\end{array}$ & $\begin{array}{l}\text { Proceso de Fabricación de Suelas y } \\
\text { Plantillas de Poliuretano }\end{array}$ \\
\hline PRODUCTO & Suelas y Plantillas \\
\hline SE INICIA EN & Recibo de orden de Producción \\
\hline SE TERMINA EN & Despacho \\
\hline
\end{tabular}

\begin{tabular}{|c|c|c}
\hline \multicolumn{3}{|c}{ ACTIVIDAD } \\
\hline 0 & Operación & 10 \\
\hline & Transporte & 6 \\
\hline & Demora & - \\
\hline & Inspección & 3 \\
\hline & Almacenamiento & - \\
\hline
\end{tabular}




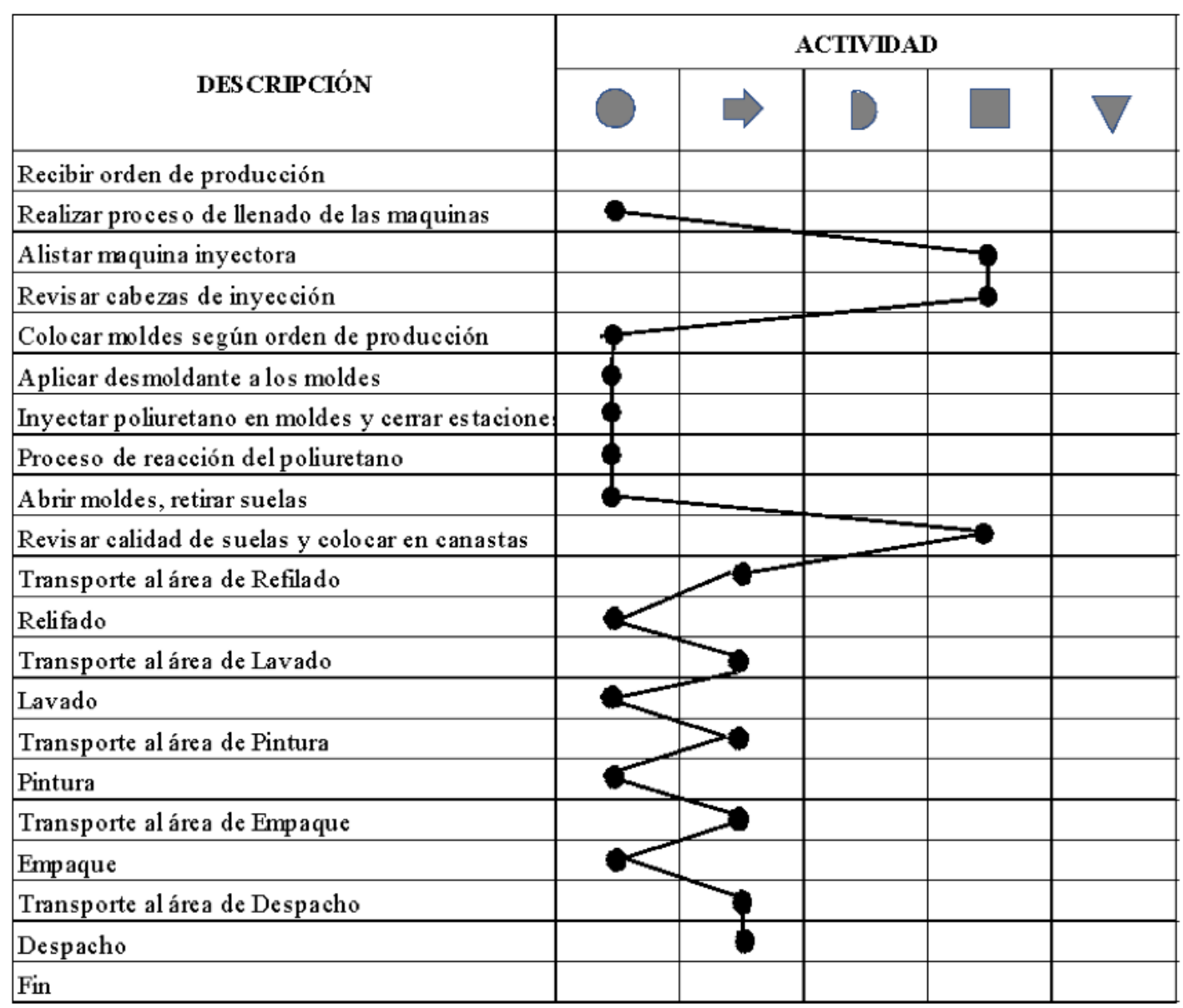

Figura 2. Diagrama de flujo del proceso de Inyección.

Fuente: Autores

\section{RESULTADOS Y DISCUSIÓN}

La población participante en esta investigación correspondió a 23 hombres y 10 mujeres, el $51.5 \%$ entre 18 y 32 años, y el $57.6 \%$ con nivel académico de primaria (Figura 3, Recuadro A). El $21.2 \%$ se desempeñaban como empacadores (Figura 3, recuadro B). La contratación del personal en su mayoría (81.8\%) correspondía a contrato indefinido y con un ingreso económico correspondiente a 1 salario mínimo legal vigente (Figura 3, recuadro $\mathrm{C}$ ). Se encontró que la no identificación del riesgo (21\%), y la falta de capacitación (42\%), estaba presente en cargos relacionados con actividades de logística (Figura 3, recuadro D). 

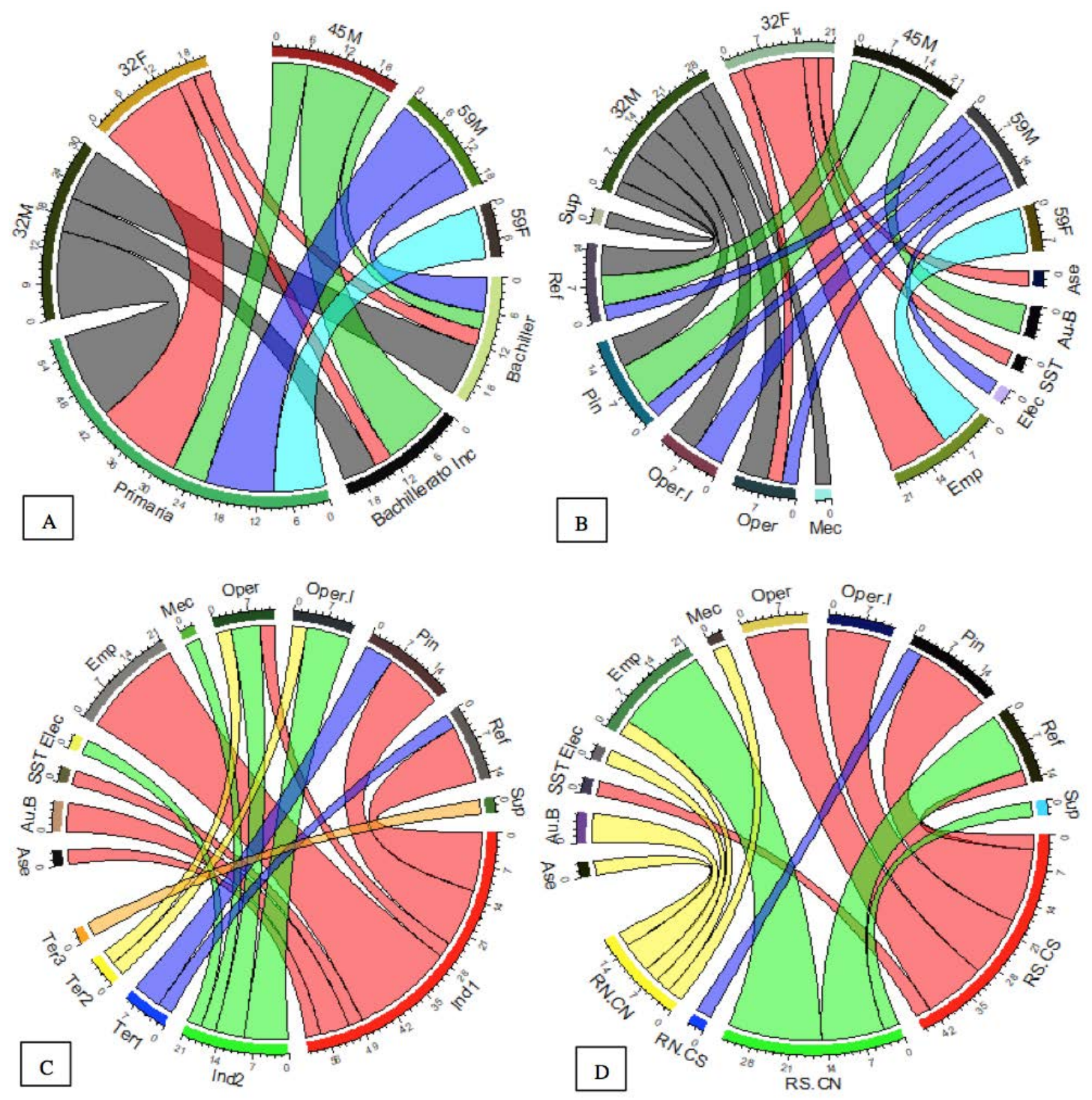

Figura 3. Graficas Circulares relacionadas con el estudio sociodemográfico.

Fuente: Autores

En la Figura 3 se observa la composición etaria, nivel académico, ingreso salarial (SMLMV), actividad desempeñada, tipo de contrato, conocimiento del riesgo y capacitación. En la parte superior de los recuadros A y B se observa el rango etario 32: 18 a 32 años, 45: 33 a 45 años y 59: 46 a 59 años. Las letras continuas corresponden a $\mathrm{F}$ : femenino y $\mathrm{M}$ : masculino. En el recuadro $A$, en el semicírculo inferior se observa la formación académica, Primaria, Bachiller: bachillerato completo y Bachillerato Inc: Bachillerato incompleto. En el recuadro B en la parte inferior se describen los cargos: Asea: Aseadora; Au.B: Auxiliar de Bodega; SST: Coordinador de SST; Elec: Eléctrico; Emp: Empacadora; Mec: Mecánico; Oper: Operario de lavado; Oper.I: Operario de maquina inyectora; Pin: Pintor; Ref: Refilador; y Sup: Supervisor. Estas clases se observan en la parte superior de los recuadros $B$ y $C$. En la parte inferior de recuadro $C$, Ter: contrato termino fijo y Ind: contrato indefinido; los números continuos corresponden al número de salarios mínimos legales vigentes que reciben como ingreso; y en 
el recuadro D, RS.CS: Reconoce el riesgo y ha recibido capacitación, RS.CN: Reconoce el riesgo y no ha recibido capacitación, RN.CS: no reconoce el riesgo y ha recibido capacitación; y RN.CN: no reconoce el riesgo y no ha recibido capacitación. Adicionalmente los colores de las bandas corresponden al porcentaje compartido entre las variables evaluadas.

La encuesta realizada al personal operativo (pintores, refiladores, auxiliares de bodega, operarios de lavado, operarios de máquinas) refleja, según se muestra en la Tabla 2 , que siete de las quince preguntas realizadas al personal superan el $50 \%$ de las respuestas negativas y estas corresponden en su mayor parte a la capacitación y entrega de elementos de protección ya sea individual, colectivos e informativos, labor que es responsabilidad de la empresa objeto de estudio.

Tabla 2. Conocimiento sobre las sustancias químicas empleadas empresa objeto de estudio.

\begin{tabular}{|c|c|c|c|}
\hline \multirow{2}{*}{$\mathbf{N}^{\circ}$} & \multirow{2}{*}{$\begin{array}{l}\text { Conocimiento sobre las sustancias químicas } \\
\text { empleadas en la empresa }\end{array}$} & \multicolumn{2}{|c|}{ CRITERIO } \\
\hline & & SI & NO \\
\hline 1 & ¿Sabe usted que sustancias químicas se manejan en la empresa? & $79 \%$ & $21 \%$ \\
\hline 2 & $\begin{array}{l}\text { ¿Alguna vez ha recibido por parte de la empresa capacitaciones sobre } \\
\text { el manejo, almacenamiento o transporte interno de sustancias químicas? }\end{array}$ & $48 \%$ & $52 \%$ \\
\hline 3 & ¿Sabe cuáles son los efectos que causan en la salud estas sustancias? & $88 \%$ & $12 \%$ \\
\hline 4 & $\begin{array}{l}\text { Si estuviéramos en el almacén ¿Usted podría identificar los productos } \\
\text { químicos almacenados en este? }\end{array}$ & $52 \%$ & $48 \%$ \\
\hline 5 & ¿Ha recibido capacitaciones sobre primeros auxilios? & $58 \%$ & $42 \%$ \\
\hline 6 & ¿La empresa cuenta con una brigada para la atención de emergencias? & $76 \%$ & $24 \%$ \\
\hline 7 & $\begin{array}{l}\text { ¿Conoce usted el procedimiento que debe seguir para la atención } \\
\text { de emergencias con alguna sustancia química? }\end{array}$ & $61 \%$ & $39 \%$ \\
\hline 8 & ¿Sabe utilizar un extintor? & $70 \%$ & $30 \%$ \\
\hline 9 & ¿La empresa les suministra elementos de protección personal? & $100 \%$ & $0 \%$ \\
\hline 10 & ¿Cuentan con duchas lava ojos? & $21 \%$ & $79 \%$ \\
\hline 11 & ¿Existe señalizaciones de peligro en las zonas de trabajo? & $12 \%$ & $88 \%$ \\
\hline 12 & ¿Existe señalizaciones de prohibición dentro de la planta? & $12 \%$ & $88 \%$ \\
\hline 13 & ¿La planta se encuentra demarcada? & $36 \%$ & $64 \%$ \\
\hline 14 & $\begin{array}{l}\text { ¿Conoce las hojas de seguridad de las sustancias químicas } \\
\text { que se manejan en la empresa? }\end{array}$ & $33 \%$ & $67 \%$ \\
\hline 15 & $\begin{array}{l}\text { ¿Conoce el programa de seguridad de las sustancias químicas } \\
\text { que maneja la empresa? }\end{array}$ & $30 \%$ & $70 \%$ \\
\hline
\end{tabular}

Fuente: Autores 
Cumplimiento de la normatividad colombiana respecto al manejo de sustancias químicas en los lugares de trabajo "Aspectos generales, manejo, almacenamiento y manejo ambiental de las sustancias químicas"

La Tabla 3 indica el resultado de la lista de chequeo, la cual fue diseñada con base en las exigencias de la normatividad colombiana respecto a aspectos generales, manejo, almacenamiento y manejo ambiental de las sustancias químicas. Esta lista de chequeo fue aplicada al profesional de seguridad y salud en el trabajo de la empresa objeto de estudio y arroja los siguientes resultados.

Tabla 3. Cumplimiento de la normatividad colombiana respecto al manejo de sustancias químicas.

\begin{tabular}{|c|c|c|}
\hline Aspectos Evaluados & Cumple (1) & No Cumple (2) \\
\hline Aspectos Generales & 3 & 8 \\
\hline Manejo & 1 & 4 \\
\hline Almacenamiento & 3 & 4 \\
\hline Transporte & 0 & 3 \\
\hline Ambiental & 0 & 4 \\
\hline Total & 7 & 23 \\
\hline \multirow{3}{*}{$\begin{array}{l}\text { RESULTADO (Valoración } \\
\text { de puntos de cumplimiento) }\end{array}$} & $22-30$ puntos & Aceptable \\
\hline & $15-21$ & Aceptable con control específico \\
\hline & Menos de 14 Puntos & No aceptable \\
\hline
\end{tabular}

Fuente: Autores

En la Tabla 3, se puede observar que de 30 puntos posibles, la empresa objeto de estudio solo cumple con 7 puntos, menos del $24 \%$ de las exigencias más importantes, en cuanto al manejo de sustancias químicas en los lugares de trabajo, por esta razón el resultado de la aplicación de esta lista de chequeo es No Aceptable por cumplir con menos de 14 puntos.
Método de evaluación del riesgo químico por inhalación y contacto con piel de la INRS. Criterios de Inclusión y exclusión para la muestra

Las Tablas 4, 5 y 6 muestran los resultados obtenidos en la aplicación del Método de evaluación del riesgo químico por inhalación y contacto con piel de la INRS, aplicados a las 10 sustancias químicas manejadas en la empresa objeto de estudio, para la fabricación de suelas y plantillas a base de poliuretano, el cual arrojó los siguientes resultados. 
Tabla 4. Determinación riesgo potencial por químicos.

\begin{tabular}{|c|c|c|c|c|c|c|c|c|c|}
\hline No & $\begin{array}{c}\text { Sustancias } \\
\text { Química }\end{array}$ & $\begin{array}{c}\text { Clase } \\
\text { de } \\
\text { Peligro }\end{array}$ & $\begin{array}{c}\text { Clase } \\
\text { de } \\
\text { Cantidad }\end{array}$ & $\begin{array}{c}\text { Clase } \\
\text { de } \\
\text { Frecuencia } \\
\text { de } \\
\text { Utilización }\end{array}$ & $\begin{array}{l}\text { Exposi- } \\
\text { ción Po- } \\
\text { tencial }\end{array}$ & $\begin{array}{c}\text { Clase } \\
\text { de Riesgo } \\
\text { Potencial }\end{array}$ & $\begin{array}{c}\text { Clase } \\
\text { de Riesgo } \\
\text { Potencial } \\
\text { (Puntua- } \\
\text { ción) }\end{array}$ & Prioridad & $\begin{array}{c}\text { Indice } \\
\text { Parcial } \\
\text { Acumula- } \\
\text { do }\end{array}$ \\
\hline 1 & $\begin{array}{l}\text { Compuesto } \\
\text { Isocianatos } \\
\text { ISN } 143\end{array}$ & 4 & 4 & 4 & 5 & 5 & 10000 & Alto & 31,94 \\
\hline 2 & Poliol HDR & 1 & 4 & 4 & 5 & 2 & 10 & Baja & 0,03 \\
\hline 3 & Aditivos & 1 & 3 & 4 & 4 & 1 & 1 & Baja & 0,00 \\
\hline 4 & Catalizadores & 3 & 3 & 4 & 4 & 3 & 100 & Media & 0,32 \\
\hline 5 & Desmoldantes & 1 & 2 & 4 & 2 & 1 & 1 & Baja & 0,00 \\
\hline 6 & Percloroetileno & 5 & 3 & 3 & 3 & 5 & 10000 & Alto & 31,94 \\
\hline 7 & $\begin{array}{l}\text { Cloruro } \\
\text { de Metileno }\end{array}$ & 5 & 3 & 3 & 3 & 5 & 10000 & Alto & 31,94 \\
\hline 8 & $\begin{array}{l}\text { Pinturas } \\
\text { o pigmentos }\end{array}$ & 4 & 3 & 4 & 4 & 4 & 1000 & Media & 3,19 \\
\hline 9 & $\begin{array}{l}\text { Diluyentes } \\
\text { para pinturas }\end{array}$ & 4 & 2 & 1 & 2 & 3 & 100 & Media & 0,32 \\
\hline 10 & Removedor & 4 & 2 & 1 & 2 & 3 & 100 & Media & 0,32 \\
\hline
\end{tabular}

Fuente: Adaptado de Instituto nacional de higiene y seguridad en el trabajo (2012)

En la tabla se determina el riesgo potencial de cada una de las sustancias químicas manejadas en la empresa, lo que permite otorgarle un nivel de prioridad a cada sustancia, además de un índice parcial acumulado, el cual, determina según la INSHT, el siguiente parámetro de riesgo: Se podrá prescindir de aquellos agentes que en su conjunto aporten menos del $20 \%$, salvo los que estén regulados por una legislación específica.
Teniendo en cuenta el parámetro de la INSHT, de las diez sustancias químicas evaluadas, siete arrojan un porcentaje menor al $20 \%$. Pero estas no son eliminadas por tener la condición de contener frases $\mathrm{H}$ como (H302, H331, H332, H350, H351), lo que las convierte en sustancias reguladas por ser nocivas, toxicas o sospechosas de provocar cáncer. 
Tabla 5. Riesgo por Inhalación químicos.

\begin{tabular}{|c|c|c|c|c|c|c|c|c|c|c|c|c|c|c|}
\hline \multicolumn{15}{|c|}{ DETERMINACIÓN DE RIESGO POR INHALACIÓN } \\
\hline \multirow{2}{*}{ No } & \multirow{2}{*}{$\begin{array}{c}\text { Sustancias } \\
\text { Química }\end{array}$} & \multicolumn{2}{|c|}{$\begin{array}{l}\text { Clase de } \\
\text { Peligro }\end{array}$} & \multicolumn{2}{|c|}{$\begin{array}{c}\text { Clase de } \\
\text { Volatilidad o } \\
\text { Pulverulencia }\end{array}$} & \multicolumn{2}{|c|}{$\begin{array}{l}\text { Procedi- } \\
\text { miento }\end{array}$} & \multicolumn{2}{|c|}{$\begin{array}{c}\text { Protección } \\
\text { Colectiva }\end{array}$} & \multicolumn{2}{|c|}{ TLV } & \multicolumn{3}{|c|}{$\begin{array}{l}\text { Riesgo por Inhalación } \\
\text { PuntuaciónInhalación = Punt. } \\
\text { Peligro x Punt. Volatilidad x } \\
\text { Punt. Procedimiento x Punt. } \\
\text { Protección Colectiva x Fcvla }\end{array}$} \\
\hline & & $\begin{array}{l}\text { D } \\
\text { Ẽ } \\
\text { U }\end{array}$ & 总 & $\begin{array}{l}0 \\
\text { U } \\
\text { Ũ } \\
\end{array}$ & 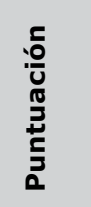 & $\begin{array}{l}0 \\
y \\
\frac{0}{v} \\
\end{array}$ & 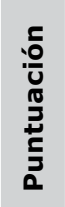 & $\begin{array}{l}0 \\
y \\
\frac{\pi}{v}\end{array}$ & 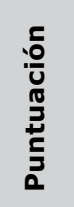 & 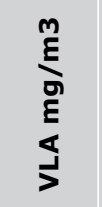 & $\sum_{4}^{\longleftarrow}$ & 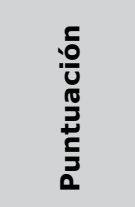 & 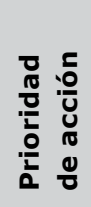 & 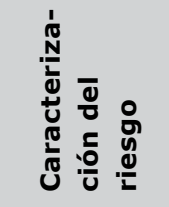 \\
\hline 1 & $\begin{array}{l}\text { Compuesto } \\
\text { Isocianatos } \\
\text { ISN } 143\end{array}$ & 4 & 1000 & 2 & 10 & 3 & 0,5 & 3 & 0,7 & 0.025 & 10 & 35000 & 1 & $\begin{array}{l}\text { Riesgo } \\
\text { Alto }\end{array}$ \\
\hline 2 & Poliol HDR & 1 & 1 & 1 & 1 & 3 & 0,5 & 3 & 0,7 & - & 100 & 35 & 2 & $\begin{array}{l}\text { Riesgo } \\
\text { Moderado }\end{array}$ \\
\hline 3 & Aditivos & 1 & 1 & 1 & 1 & 3 & 0,5 & 3 & 0,7 & - & 100 & 35 & 2 & $\begin{array}{l}\text { Riesgo } \\
\text { Moderado }\end{array}$ \\
\hline 4 & $\begin{array}{l}\text { Catalizado- } \\
\text { res }\end{array}$ & 3 & 100 & 2 & 10 & 3 & 0,5 & 3 & 0,7 & 221 & 1 & 350 & 2 & $\begin{array}{l}\text { Riesgo } \\
\text { Moderado }\end{array}$ \\
\hline 5 & $\begin{array}{l}\text { Desmoldan- } \\
\text { tes }\end{array}$ & 1 & 1 & 2 & 10 & 4 & 1 & 3 & 0,7 & 400 & 1 & 7 & 3 & $\begin{array}{l}\text { Riesgo } \\
\text { Bajo }\end{array}$ \\
\hline 6 & $\begin{array}{l}\text { Percloroeti- } \\
\text { leno }\end{array}$ & 5 & 10000 & 2 & 10 & 3 & 0,5 & 3 & 0,7 & 172 & 1 & 35000 & 1 & $\begin{array}{l}\text { Riesgo } \\
\text { Alto }\end{array}$ \\
\hline 7 & $\begin{array}{l}\text { Cloruro } \\
\text { de Metileno }\end{array}$ & 5 & 10000 & 3 & 100 & 3 & 0,5 & 3 & 0,7 & 177 & 1 & 350000 & 1 & $\begin{array}{l}\text { Riesgo } \\
\text { Alto }\end{array}$ \\
\hline 8 & $\begin{array}{l}\text { Pinturas o } \\
\text { pigmentos }\end{array}$ & 4 & 1000 & 2 & 10 & 4 & 1 & 3 & 0,7 & 275 & 1 & 7000 & 1 & $\begin{array}{l}\text { Riesgo } \\
\text { Alto }\end{array}$ \\
\hline 9 & $\begin{array}{l}\text { Diluyentes } \\
\text { para pintu- } \\
\text { ras }\end{array}$ & 4 & 1000 & 2 & 10 & 3 & 0,5 & 3 & 0,7 & 724 & 1 & 3500 & 1 & $\begin{array}{l}\text { Riesgo } \\
\text { Alto }\end{array}$ \\
\hline 10 & Removedor & 4 & 1000 & 3 & 100 & 3 & 0,5 & 3 & 0,7 & 177 & 1 & 35000 & 1 & $\begin{array}{l}\text { Riesgo } \\
\text { Alto }\end{array}$ \\
\hline
\end{tabular}

Fuente: Adaptado de Instituto nacional de higiene y seguridad en el trabajo (2012).

En la tabla 5 se determina el riesgo por inhalación, el cual se halla mediante la multiplicación de las puntuaciones arrojadas por las variables Clase de peligro, Clase de volatilidad, Clase de Procedimiento, Tipo de protección colectiva y el valor de corrección para el
VLA. Esto demuestra un riesgo alto por inhalación para las sustancias Isocianato, Percloroetileno, Cloruro de Metileno, Pinturas, Diluyentes para pinturas y Removedor, todas estas consideradas sustancias nocivas, toxicas o cancerígenas. 
Tabla 6. Riesgo por Contacto químico con la Piel.

\begin{tabular}{|c|c|c|c|c|c|c|c|c|c|}
\hline \multicolumn{10}{|c|}{ DETERMINACIÓN DE RIESGO POR CONTACTO PIEL } \\
\hline \multirow[b]{2}{*}{ No } & \multirow[b]{2}{*}{$\begin{array}{c}\text { Sustancias } \\
\text { Química }\end{array}$} & \multicolumn{2}{|c|}{$\begin{array}{c}\text { Clase } \\
\text { de Peligro }\end{array}$} & $\begin{array}{l}\text { Clase de } \\
\text { Superficie } \\
\text { Expuesta }\end{array}$ & \multicolumn{2}{|c|}{$\begin{array}{l}\text { Frecuencia } \\
\text { de Exposición }\end{array}$} & \multicolumn{3}{|c|}{$\begin{array}{l}\text { Riesgo por Contacto Piel }= \\
\text { Punt. Peligro x Punt. Superficie } \\
\text { x Punt. Frecuencia }\end{array}$} \\
\hline & & $\begin{array}{l}0 \\
\text { o } \\
\end{array}$ & 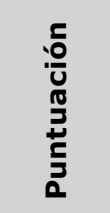 & 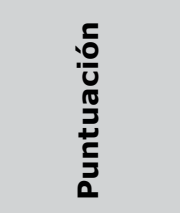 & $\begin{array}{l}0 \\
y \\
\tilde{c} \\
\end{array}$ & 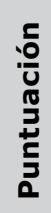 & 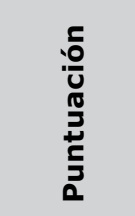 & 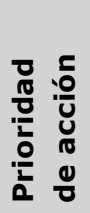 & 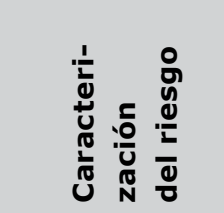 \\
\hline 1 & $\begin{array}{l}\text { Compuesto } \\
\text { Isocianatos } \\
\text { ISN } 143\end{array}$ & 4 & 1000 & 2 & Permanente & 10 & 20000 & 1 & Riesgo Alto \\
\hline 2 & Poliol HDR & 1 & 1 & 2 & Permanente & 10 & 20 & 3 & Riesgo Bajo \\
\hline 3 & Aditivos & 1 & 1 & 2 & Permanente & 10 & 20 & 3 & Riesgo Bajo \\
\hline 4 & Catalizadores & 3 & 100 & 2 & Permanente & 10 & 2000 & 1 & Riesgo Alto \\
\hline 5 & Desmoldantes & 1 & 1 & 2 & Permanente & 10 & 20 & 3 & Riesgo Bajo \\
\hline 6 & Percloroetileno & 5 & 10000 & 2 & Frecuente & 5 & 100000 & 1 & Riesgo Alto \\
\hline 7 & $\begin{array}{l}\text { Cloruro } \\
\text { de Metileno }\end{array}$ & 5 & 10000 & 2 & Frecuente & 5 & 100000 & 1 & Riesgo Alto \\
\hline 8 & $\begin{array}{l}\text { Pinturas } \\
\text { o pigmentos }\end{array}$ & 4 & 1000 & 2 & Permanente & 10 & 20000 & 1 & Riesgo Alto \\
\hline 9 & $\begin{array}{l}\text { Diluyentes } \\
\text { para pinturas }\end{array}$ & 4 & 1000 & 2 & Ocasional & 1 & 2000 & 1 & Riesgo Alto \\
\hline 10 & Removedor & 4 & 1000 & 2 & Ocasional & 1 & 2000 & 1 & Riesgo Alto \\
\hline
\end{tabular}

Fuente: Adaptado de Instituto nacional de higiene y seguridad en el trabajo (2012)

La Tabla 6 muestra la evaluación y determinó que las sustancias químicas con riesgo más alto por contacto son precisamente las mismas arrojas por la evaluación de riesgo por inhalación. Esto se debe a que las variables utilizadas para la avaluación de ambos riesgos son las mismas (Clase de peligro y Frecuencia de exposición); sin embargo, para el riesgo por contacto se tiene en cuenta la clase de superficie expuesta. Esto se determina teniendo en cuenta que las actividades son manuales y el tipo de dotación que les suministran a los trabajadores. Por eso se escoge la puntuación 2 parte expuesta extremidades superiores.

\section{Almacenamiento}

Para el almacenamiento de sustancias químicas, Figura 4, se tuvo en cuenta las recomendaciones de Granada et al, (2015), estableciéndose que la empresa no cuenta con un solo lugar destinado para tal fin. Las canecas y galones con sustancias químicas están ubicados en toda la planta; se observan recipientes sin etiquetas; las hojas de seguridad no están publicadas en el almacén; además, no se aplica la compatibilidad de elementos al momento de almacenar. Se observa material altamente combustible almacenado junto con material inflamable o reactivo, lo cual puede generar riesgo de incendios o explosiones por incompatibilidad de productos químicos. 

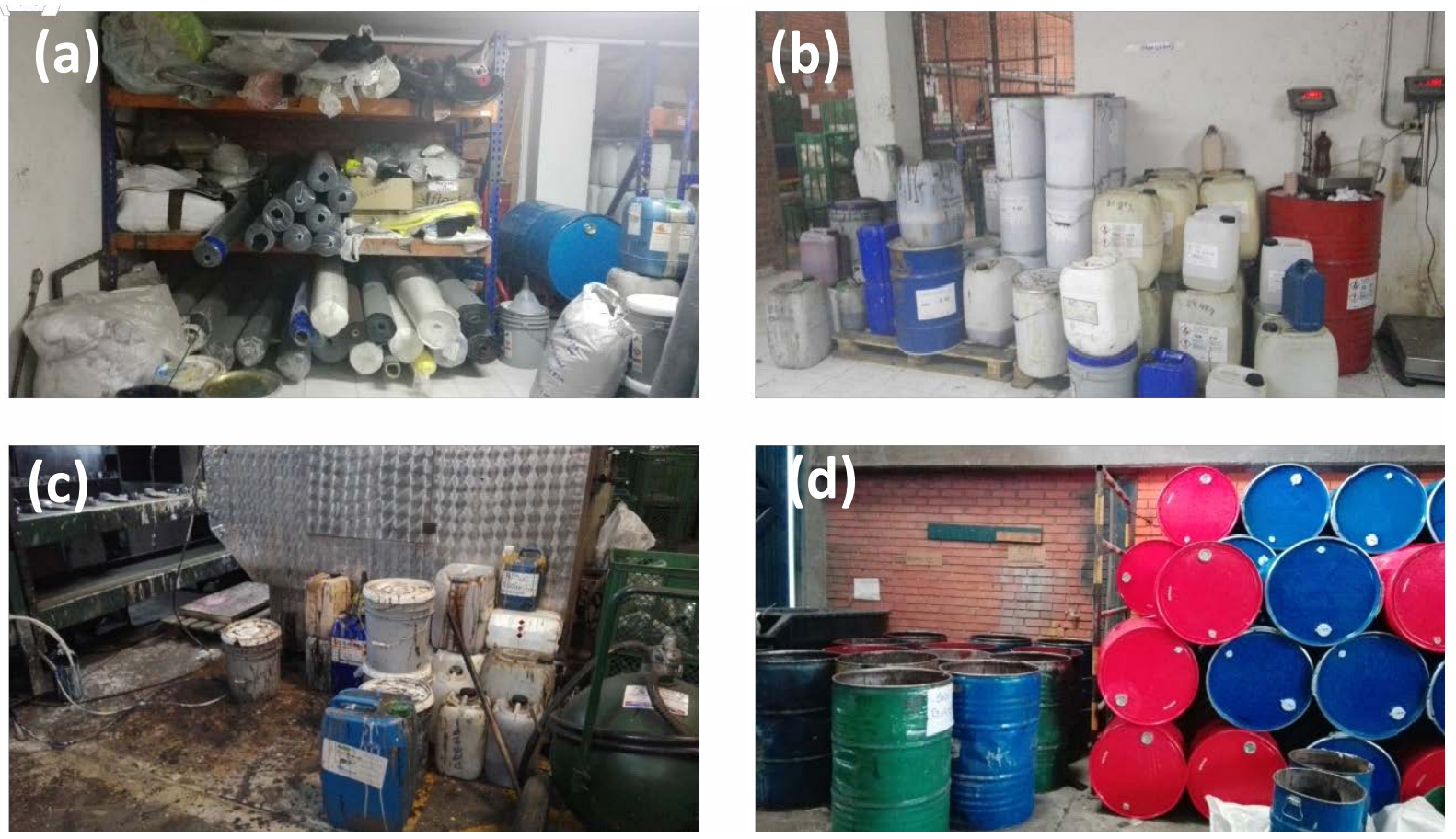

Figura 4. Almacenamiento de insumos y sustancias químicas: (a) Almacén - rollos de tela, plástico al lado de sustancias químicas, (b) Almacén - Pinturas y poliol sin estibar ni etiquetar, (c) Cabina de pinturas - sin etiquetas y (d) Zona de disposición final - Tinas desocupadas con tinas llenas de sustancias químicas.

Fuente: Autores

\section{Manejo y Uso}

En las fotografías presentadas en la Figura 5 se muestra un empleado realizando la tarea de preparación y llenado de las maquinas inyectoras. Esta labor se realiza a la hora del almuerzo, cuando estas máquinas paran la operación. Un solo empleado realiza esta operación sin supervisión, y sin ayuda para el transporte interno de los galones. Además, este debe subir a una altura de por lo menos 1,20 metros para llenar la maquina inyectora de suelas y esta labor también la realiza solo. No existe supervisión y si se presentara el caso de alguna emergencia y el empleado llegue a necesitar ayuda, todo el personal se encuentra a una distancia más o menos de unos 200 metros separados por una bodega que no sería posible escucharlo. 

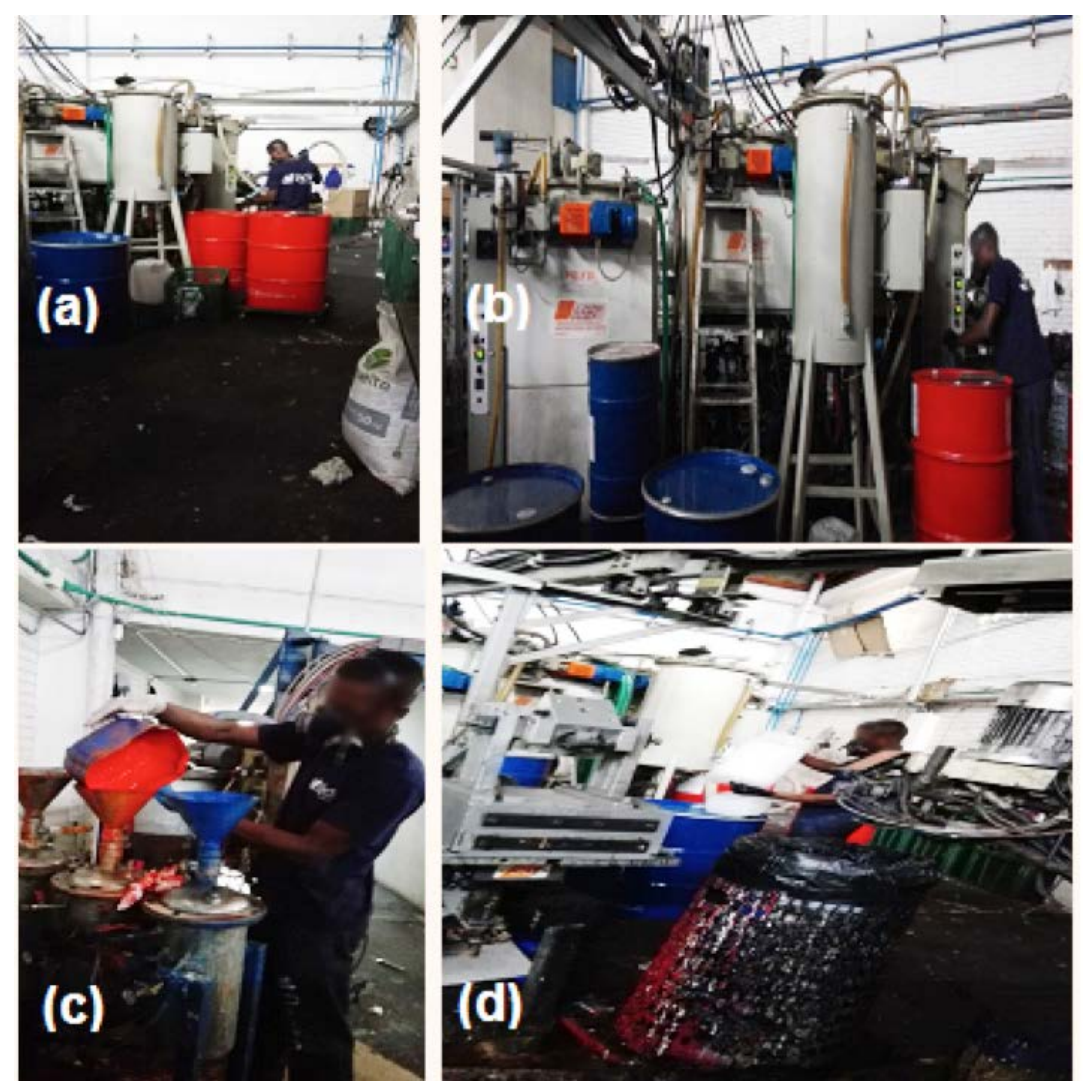

Figura 5. Manejo de sustancias químicas en el llenado de las maquinas inyectoras: (a) (b) llenado de maquina inyectora de suelas, (c) llenado de maquina inyectora de plantillas y (d) llenado de maquina inyectora de suelas.

Fuente: Autores

\section{Control de Ingeniería \\ y Protecciones Colectivas}

La empresa cuenta con un área total de 1.900 $\mathrm{m} 2$, separada en 3 bodegas las cuales se comunican entre sí. La bodega donde está la maquina inyectora solo cuenta con 2 extractores de aire en mal estado, como se muestra en la Figura 6, pues, al momento de la inspección, estos no funcionaban y se encontraron obstruidos y sucios, al igual que los extractores de la zona de pinturas que, aunque sí funcionan, son insuficientes para extraer los vapores generados por las 3 cabinas de pinturas que existen en la empresa. El almacén de sustancias químicas solo cuenta con un extractor. En total, para un área de $1.900 \mathrm{~m} 2$ donde se manejan sustancias químicas que generan toxicidad por inhalación, solo hay 5 extractores y 2 están en mal estado. 

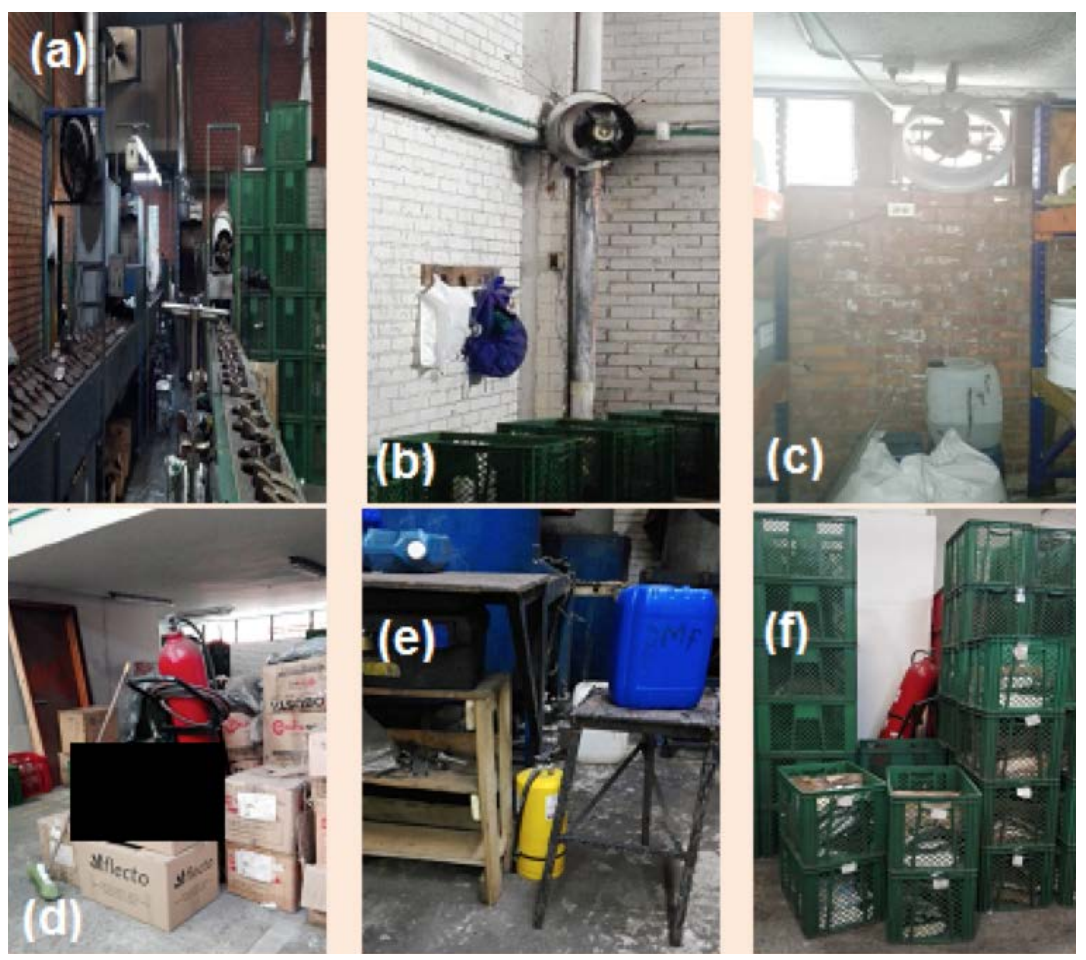

Figura 6. Extractores de Vapores y Extintores: (a) Extractores cabinas de Pintura, (b) Extractor bodega 1,

(c) Extractor almacén, (d) Extintor bodega 3 con los depósitos de basura, (e) Extintor bodega 2 al lado de las cabinas de pintura y (f) Extintor bodega 3 con los depósitos de basura.

Fuente: Autores

\section{Elementos de Protección Personal}

En la Figura 7 se puede observar que el personal tiene un manejo inadecuado de los elementos de protección personal, además no existen controles que permitan exigir el uso
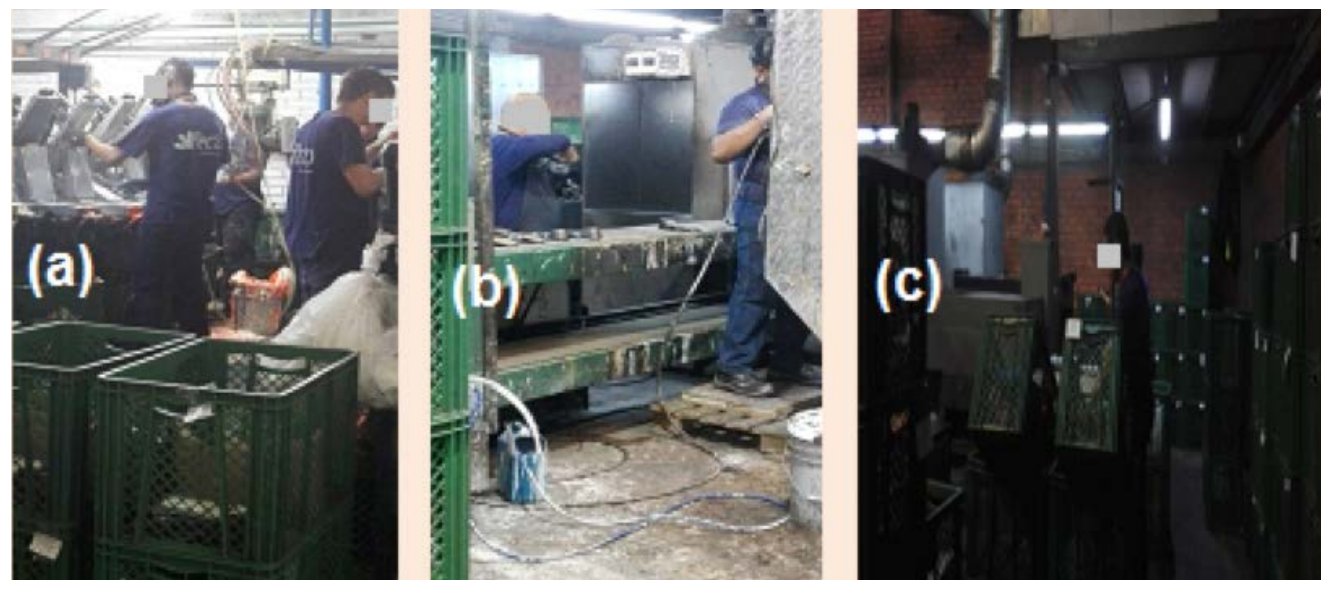

Figura 7. Uso de Elementos de protección personal: (a) Maquina inyectora de plantilla, (b) Cabina de pinturas y (c) Cabina de pinturas.

Fuente: Autores 
La empresa proporciona elementos de protección personal; sin embargo, a los empleados no les dan el tratamiento que asegure su protección, como se evidencia en la Figura 8.
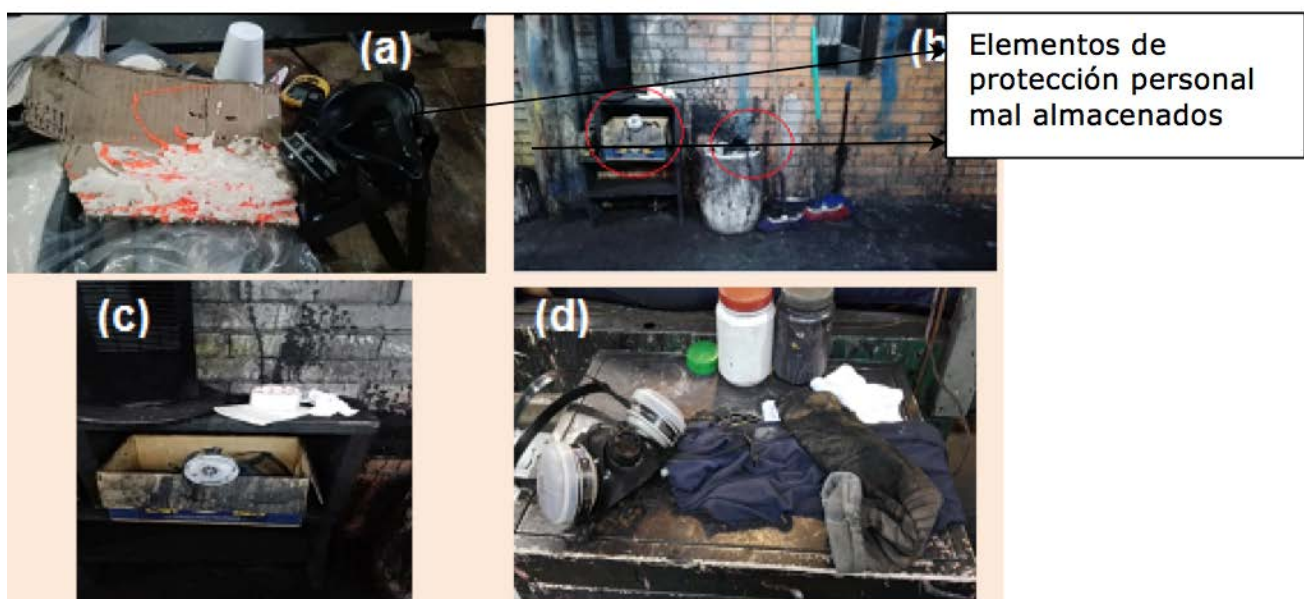

Figura 8. Cuidado de los Elementos de protección personal: (a) maquina inyectora de suelas - Respirador con filtro al lado de sustancias químicas, (b) Cabinas de pintura - Respiradores en cajas con trapos y encima de recipientes impregnados de sustancias químicas; (c) Cabinas de pintura - Respiradores en cajas untadas de pinturas, (d) Cabinas de pintura - Respiradores con trapos impregnados de sustancias químicas.

Fuente: Autores

\section{Orden y Aseo}

Como se muestra en la Figura 9, la falta de locativo los cuales si no son controlados puecontrol del orden y el aseo evidencia condiciones inseguras por la exposición al peligro químico, y a otros peligros como condiciones de seguridad mecánico, tecnológicos, eléctrico, den generar un accidente de trabajo o una enfermedad laboral lo cual afecta la productividad, calidad y seguridad en la empresa objeto de estudio.

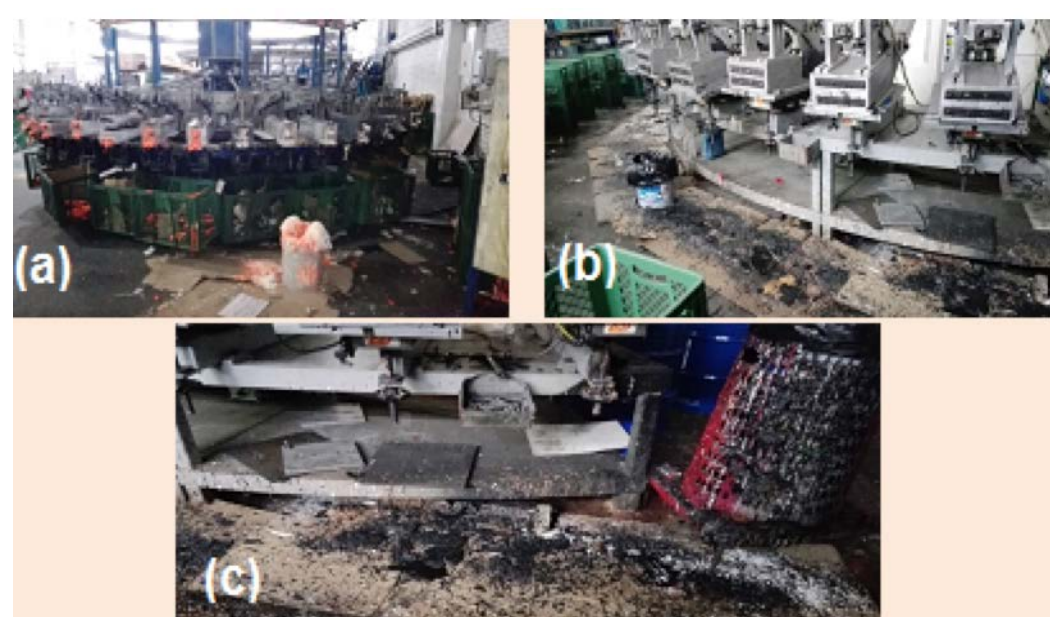

Figura 9. Orden y Aseo: (a) maquina inyectora de plantillas - Poliuretano derramado en el suelo y en recipientes plásticos sin tapar, (b) maquina inyectora de suelas - Poliuretano derramado en el suelo y en recipientes plásticos sin tapar y (c) maquina inyectora de suelas - Poliuretano derramado en el suelo y sobre cartón contaminando desechos reciclables. 


\section{Disposición Final}

Los residuos sólidos generados por la empresa se mezclan con residuos reciclables y con residuos peligrosos, y ambos se recolectan en los mismos recipientes que posteriormente se entregan a la empresa de aseo. Además, las tinas metálicas se venden a una persona natural (reciclador), quien las recoge en una carretilla en la que carga los sobrantes de químicos que estas puedan tener. Queda el interrogante de cuál será la disposición final de estas. Como se observa en la Figura 10, la empresa objeto de estudio no cuenta con un procedimiento guía que le permita realizar una buena disposición final de los residuos, algunos de estos pueden ser contaminantes para el agua u organismos acuáticos, y estos se tratan como desechos ordinarios y se mezclan con papel, cartón e incluso desechos biológicos, como se puede observar en la foto.
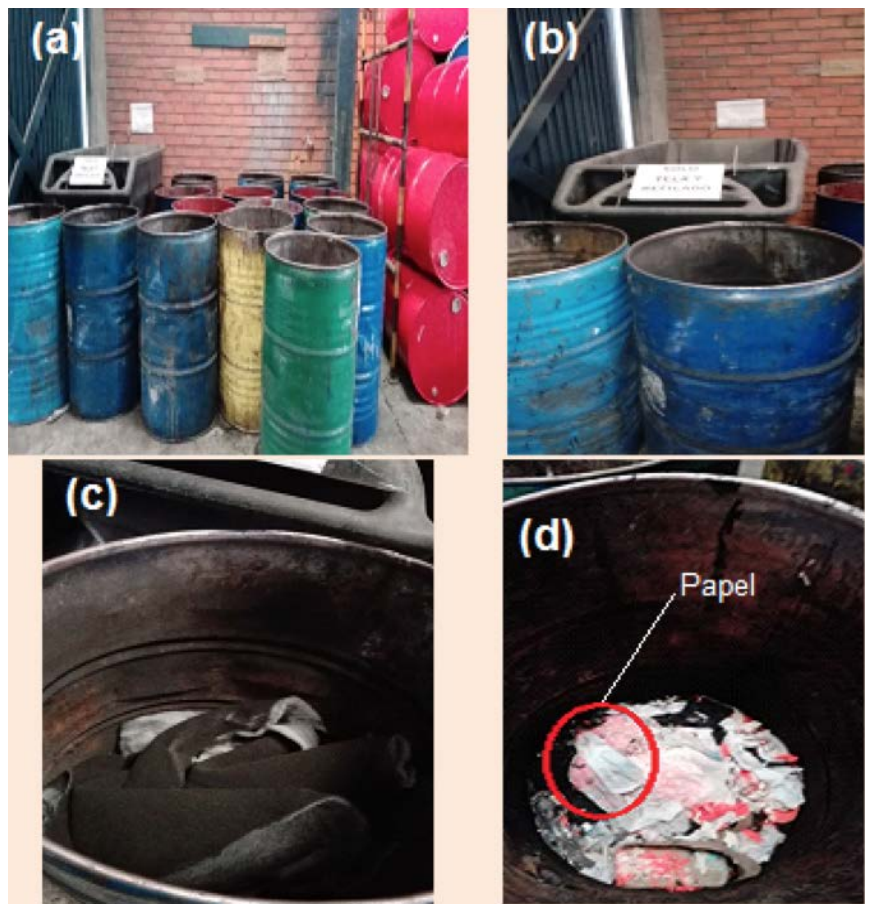

Figura 10. Disposición Final de los residuos: (a) (b) Bodega 3 zona de disposición final, (c) zona de disposición final - Telas en tinas de sustancias químicas, (d) zona de disposición final Desechos biológicos en tinas de sustancias químicas con papel.

Fuente: Autores

\section{Procedimiento seguro de sustancias químicas}

Con el fin de definir los lineamientos de seguridad para el manejo de sustancias químicas, de minimizar los riesgos laborales e impactos ambientales y así garantizar la salud e integridad física de los trabajadores, la protección del patrimonio de la empresa y protección del medio ambiente, se diseñó un procedimiento para el manejo seguro de sustancias químicas. El procedimiento se aplicó para todos los trabajadores, contratistas y proveedores que desarrollen actividades asociadas al manejo de sustancias químicas en la empresa objeto de estudio; además, cuenta con instructivos para los procesos de manejo y uso de sustancias químicas, almacenamiento, disposición final, elementos de protección personal, plan de 
contingencia, transporte interno, de inspección pre operacional de las maquinas o herramientas, lavado de suelas, primeros auxilios.

Para la implementación del procedimiento para el manejo seguro de sustancias químicas en la empresa de fabricación de suelas y plantillas a base de Poliuretano de la ciudad de Cali, Valle en el 2018, se tuvieron en cuenta tres aspectos importantes:

La conformación de un grupo para la implementación, control y seguimiento del procedimiento, el cual debe estar conformado por los encargados del almacén, el profesional de Seguridad y Salud en el Trabajo y por lo menos un operario de cada sección del proceso cuyo objetivo será capacitar, poner en marcha, evaluar y verificar el cumplimiento del procedimiento.

La formación y la capacitación hacen parte del eje fundamental en la fase de implementación; de su continuidad depende el mantenimiento y continua mejora del procedimiento.

La implementación la política de minimización de los residuos sólidos peligrosos y adoptar procesos para medir el cumplimiento de las metas planteadas.

La peligrosidad de algunas sustancias químicas utilizadas para la fabricación de suelas y plantillas a base de poliuretano es alta, tanto que la agencia de Servicio de Salud Pública Agencia para Sustancias Tóxicas y el Registro de Enfermedades de EE.UU., cataloga a los isocianatos (TDI y MDI) como sustancias químicas muy reactivas. Además de esto, un estudio en animales expuestos oralmente a TDI reportó aumentos en la tasa de tumores del páncreas, las glándulas mamarias y el hígado (Agencia para sustancias tóxicas y registro de enfermedades, 2015). El Instituto Nacional de Ciencias de Salud Ambiental (NIEHS) considera que es razonable anticipar que el TDI es una sustancia carcinogénica en seres humanos. Aunque la EPA no ha clasificado el TDI en cuanto a carcinogenicidad (ATSDR, 2015). Aparte de los isocianatos, también se utilizan sustancias como pinturas, catalizadores, percloroetileno, cloruro de metileno, las cuales sí están catalogadas por la IARC como sospechosas de provocar cáncer tipo A2.

\section{CONCLUSIONES}

Se diagnosticó el manejo de las sustancias químicas según los procesos desarrollados por la empresa, por la mezcla de sustancias, con alta exposición y la inadecuada disposición de los residuos.

El procedimiento guía aplicado, contribuye a una producción más limpia por promover una mejor disposición de los residuos peligrosos que servirá como instrumento para concientizar a la población trabajadora en este tipo de empresas y superar la debilidad que resultó del diagnóstico, donde se encontraron 10 sustancias químicas consideradas peligrosas, 4 de ellas clasificadas por la IARC como grupo A2, sospechosas de provocar cáncer, además de ser tóxicas y nocivas para la salud y el medio ambiente.

Según parámetros de la INSHT de las 10 sustancias evaluadas, 7 tienen un porcentaje menor al 20\%; sin embargo, no son eliminadas por contener frases $\mathrm{H}(\mathrm{H} 302, \mathrm{H} 331, \mathrm{H} 332$, H350 y H351) lo que las convierte en sustancias reguladas por ser nocivas, tóxicas o sospechosas de provocar cáncer.

\section{RECOMENDACIONES}

Cumplir con los requerimientos de ley mediante un plan de capacitación en seguridad y salud en el trabajo, sistema de vigilancia epidemiológica para riesgo químico, gestión y manejo de sustancias peligrosas y su disposición final. 
Realizar mantenimiento preventivo y correctivo, pero cada vez más orientado hacia lo preventivo o predictivo, que implica un monitoreo constante y una "hoja de vida" para cada equipo o máquina que permita llevar controles para su revisión oportuna.

\section{CONTRIBUCIÓN DE LA AUTORÍA}

Primer autor: Metodología, investigación, análisis de datos, conceptualización, escritura - borrador original. Segundo autor: Investigación, conceptualización, análisis de datos. Tercer autor: Logística, escritura, revisión y edición. Cuarto autor: análisis de datos, revisión y edición.

\section{AGRADECIMIENTOS}

Al acompañamiento y aportes del semillero de investigación en gestión en seguridad y salud en el trabajo, especialmente Johanna Domínguez Orejuela, por su desempeño y contribución. Al decanato de investigaciones de la UNIAJC, por su acompañamiento.

\section{LITERATURA CITADA}

Agencia para sustancias tóxicas y registro de enfermedades. (10 de Septiembre de 2015). Resumén de salud pública, Tolueno Diisocianato (TDI) y Metilendifenil Diisocianato (MDI). Recuperado el 4 de Febrero de 2019, de https://www.atsdr. cdc.gov/es/phs/es_phs206.pdf

Alonso, M. B. (Febrero de 2014). El contacto de agentes químicos con la piel y los ojos: su evaluación y formas de evitarlo. Seguridad y Salud en el Trabajo, 76, pp. 6 -15.

Anaya Orbis, G. (2015). Estudio de riesgo higiénico por inhalación de productos químicos. Estudio (Tesis de Maestría). Universidad Miguel Hernández, España.

ATSDR - Agencia para Sustancias Tóxicas y el Registro de Enfermedades. (2015). Resumen de Salud Pública Tolueno Diisocianato (TDI) Y Metilendifenilo Diisocianato (MDI). E.U. Recuperado de https://www.atsdr.cdc.gov/es/phs/es phs206.pdf
Calera, A, Roel, J., Casal, A., Gadea, R., y Rodrigo F. (2005). Riesgo Químico Laboral: Elementos para un Diagnostico en España. Revista Española de Salud Pública, 79(2), 283-295.

Congreso de la República (1993). LEY 55. Por medio de la cual se aprueba el convenio número 170 y la recomendación número 177 sobre la seguridad en la utilización de productos químicos en el trabajo. Bogotá D.C.

EPA - Enviromental Protection Agency. (2017). Impacto de los compuestos orgánicos volátiles en la calidad del aire interior. Recuperado de https:// www.epa.gov/indoor-air-quality-iaq/volatile-organic-compounds-impact-indoor-air-quality

Fasecolda (23 de Octubre de 2011). RL datos riesgos laborales. Recuperado el 2018 de Agosto de 20, de https://consultas.fasecolda.com/rldatos/

Francelly Sánchez, J. P. (2014). Eficacia de las Medidas Preventivas y Evaluación del Riesgo Químico en una Empresa Avícola. Revista Colombiana de Salud Ocupacional, 4(2), 5 - 11. https://doi. org/10.18041/2322-634X/rcso.2.2014.4899

Franco, J., Bernaola, M., Gálvez, V., Sánchez, P., Sánchez, M., Sousa, C., ..... Tejedor, J. (2010). Riesgo Químico: Sistemática para la Evaluación Higiénica. Madrid, España.

Gisbert, E. V. (2018). Sistema globalmente armonizado (GHS). Elche, España.

Granada, L. F., Vallejo, L. A., Moreno, S., y Toro, E. (2015). Modelo de gestión integral para el manejo de residuos sólidos peligrosos. Cali, Colombia: Editorial Bonaventuriana.

Granada Aguirre, L. F., Vallejo Morán, L. A., y Alvaréz Castro, N. (2019). Proyectos ambientales para la minimización de residuos: Producción Limpia. Cali: Ediciones de la U.

Instituto colombiano de normas técnicas y certificación (2012). Guía técnica colombiana GTC-45. Guía para la identificación de los peligros y la valoración de los riesgos en seguridad y salud ocupacional. Recuperado de https://idrd.gov.co/ sitio/idrd/sites/default/files/imagenes/gtc45.pdf

Instituto nacional de higiene y seguridad en el trabajo. (2012). Instituto nacional de higiene y seguridad en el trabajo. Recuperado el 13 de 12 de 2018, de https://www.insst.es/ documents/94886/326879/937w.pdf/9f3ff227acfa-46b2-8613-355f5d057ad7 
Martínez J. (2015). Riesgo por Exposición a Isocianatos. Valencia: Ibermutuamur.

Ministerio de Salud. (2017). LINEAMIENTOS PARA LA IMPLEMENTACIÓN DEL SISTEMA GLOBALMENTE ARMONIZADO DE CLASIFICACIÓN Y ETIQUETADO DE PRODUCTOS QUÍMICOS EN COLOMBIA COMPETENCIAS DEL SECTOR SA$L U D$. Bogotá.

Ministerio de Ambiente. (2018). Libro Naranja de las Naciones Unidas. Obtenido de http://quimicos.minambiente.gov.co/index.php/gestion-desustancias-quimicas/sistema-globalmente-armonizado/libro-naranja-de-las-naciones-unidas

Ministerio de Ambiente. (2018). Libro Púrpura de las Naciones Unidas. Obtenido de http://quimicos.minambiente.gov.co/index.php/gestion-desustancias-quimicas/sistema-globalmente-armonizado/libro-purpura-de-las-naciones-unidas

Ministerio de ambiente, vivienda y desarrollo territorial (MAVDT). (30 de diciembre de 2005). Decreto 4741. Por el cual se reglamenta parcialmente la prevención y manejó de los residuos o desechos peligrosos generados en el marco de la gestión integral. Bogotá D.C, Colombia.

Ministerio de Trabajo. (26 de Mayo de 2015). Decreto 1072. Por medio del cual se expide el Decreto Único Rglamentario del Sector Trabajo. Obtenido de http://www.mintrabajo.gov.co/documents/20147/50711/DUR+Sector+Trabajo+Ac tualizado+a+Abril+de+2017.pdf/1f52e341-4def8d9c-1bee-6e693df5f2d9
Naciones Unidas. (2015). Sistema Globalmente Armonizado de Clasificación y Etiquetado de Productos Químicos (SGA). Nueva York y Ginebra.

Organización internacional del trabajo (OIT) (2014). La Seguridad y la Salud en el uso de Productos Químicos en el Trabajo. http://www. ilo.org/wcmsp5/groups/public/@ed_protect/@ protrav/@safework/documents/publication/ wcms_235105.pdf

Patiño Flores, R. I. (Febrero de 2017). Riesgo químico y salud ambiental en Colombia: Estudio de caso con hidrocarburos aromáticos (Tesis de Doctorado). Universidad Miguel Hernández de Elche, España.

Río, J. P. (2011). Reglamento CLP sobre Clasificación, Etiquetado y Envasado de Sustancias y Mezclas.

Rodríguez, S. (2008). Aplicación de métodos simplificados de evaluación del riesgo químico con efectos para la salud. Seguridad y salud en el trabajo, pp. 28 - 39.

Vargas Ramos, Y., y Marrugo Negrete, J. (2014). Exposición a COVs en fábricas de muebles de dos poblaciones del norte de Colombia. Revista de Salud Pública, 16(6), 834-846. https://doi. org/10.15446/rsap.v16n6.38585

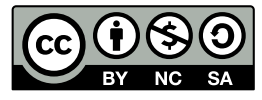


